\title{
Competence-based learning and societal awareness: Building up experiences within the discipline of interior architecture
}

\author{
Vallet, Nathalie; Somers, Inge; Corthaut, Michel
}

Faculty of Design Sciences, University of Antwerp, Belgium.

\begin{abstract}
By means of the bachelor proof, students of interior architecture of the University of Antwerp (Faculty of Design Sciences) are stimulated to design interiors for real-life public libraries in view of particular societal challenges. During three subsequent years the teaching staff elaborated a set of learning objectives and activities that jointly form a competence-based learning process focussed on the development of the societal awareness of design students. In this paper we report on the intermediate experiences of the teachning staff and the students as indicated by a set op mainly qualitative data. In short it concerns four lessons learned relating to the over- and underestimation of (i) disciplinary filters, (ii) comfort-zones, (iii) motivating complexities and (iv) copy-cat behavior.
\end{abstract}

Keywords: societal awareness, competence-based learning, academic bachelor interior architecture. 


\section{Introduction}

Since the end of the eighties, many public institutions are reconsidering the design of their public interior in order to meet a variety of societal challenges such as life-long learning, digitalization, sustainability and social diversity (Dunleavy, et al., 2006; Koliba et al., 2010). Emphasizing for instance taylormade, durable and easy-accessible public services clearly demands for a particular, 'fitting' interior design of their public buildings.

One such public institution is the public library. Throughout Europe and far beyond, public libraries are redefining the reason of their existence (Aabo, 2005; Dahlkild, 2011; Vallet, 2015). By doing so, their societal added value clearly transcends the traditional image of a 'storage for lending and borrowing books'.Thus, public libraries become for instance (digitalized) information and learning centers, active defenders of equal rights (eg. supporting the social and cultural needs of vulnerable citizens), and facilitators of public encounter and social cohesion. The remaining challenge is however: how can public libraries implement these new ambitions? What does this imply, not only in terms of activities but also in terms of appropriate library buildings and spaces?

In order to take up the previously mentioned design challenge, our future society is in need of interior architect students that can sense these societal ambitions and integrate them into the interior design process that generates 'fitting' or suitable interior designs (Giunta, 2009; Attiwill, 2011; Caan, 2011; Cunningham, 2014).

Within the faculty of Design Sciences of the University of Antwerp (Belgium), an explorative project has been launched to stimulate the societal competence-based learning of interior architect students. During three subsequent years, the bachelorproof students are assigned to make designs that explicitly fit the particular societal challenges of a selected set of real-life public libraries in Flanders (i.e. case-studies).

In this paper we will present and discuss the intermediate experiences of the teaching staff and the students involved. Due to the explorative and incremental nature of the project, a well-defined set of quantitative ex-post measurements are (presently) lacking. Nonetheless, we have collected an interesting set of relevant qualitative information (i.e. semi-structured interviews, focus goup debates) on the basis of which a first and preliminary set of insights as well as associated lessons learned can already been defined and discussed.

\section{Methodological design of the project}

\subsection{The concept of competence-based learning}

When considering the theoretical concept of competence-based learning, a competence can be defined as an integrated set of knowledge, skills and attitudes (Burke, 1990; Hoogveld et 
al., 2005). From a constructivist epistemological point of view, the learning process is considered to be a kind of quest that is explicitly modelled by the student himself. Thus, the student will elaborate gradually his or her own learning targets and ambitions. Not the final result is the central focus of the learning process, but rather the quest itself. In a competence-based learning process, the real world and a realistic simulation of the professional future of the student is crucial. Gradually, a confrontation with authentic pofessional settings will stimulate the development of appropriate insights as well as skills and attitudes. Thus, the teacher becomes a coach who gradually (re)contextualizes the developed competences that the student has learned. As such and on the basis of real-life contextualizations, the competences of the student will gradually become fine-tuned and professionalized.

Although the concept of competence-based learning was initially focussed on technical and vocational learning, at present it is also applied in higher education programs and academic studies.

When operationalizing the concept of competence-based learning within the project, it concerns the development of knowledge, skills and attitudes needed to sense and understand the particularities of the societal challenges of real-life public libraries in order to improve the interior design process of their buildings and spaces, and to guarantee a (more) 'fitting' in stead of a general, uniform library design.

\subsection{The concept of societal awareness}

The concept of societal awareness refers to particular future societal challenges of real-life public institutions. The awareness implies (i) discovering and understanding these societal particularities and (ii) taking them explicitly into consideration when designing the interior of the public institution involved.

When operationalizing the concept of societal awareness in the subsequent three years, the selected public institution was held stable and concerned Flemish public libraries. The major reasons for choosing them are (i) the dynamic change in their future societal challenges and ventilated redesign needs, and (ii) the familiarity of our students with this type of public institution (i.e. libraries are part of their daily life). Thus the presence of an authentic professional setting was guaranteed.

The first year consisted of two case-studies focussing on important library target groups. The cases were (i) the public library in Destelbergen and its particular focus on children and youngsters and (ii) the public library of Lange Munte in Kortrijk and its particular focus on a divers neighbourhood population in terms of age, gender and nationality. The second year consisted of two case-studies focussing on the digitalization hype, being (i) the public library in Elsene near Brussels and its particular focus on the direct neighborhood and 
needed makerspaces, and (ii) the public library in Diksmuide and its particular focus on digitalizing a previous church building for a divers library audience. The third year consisted of one joint case-study focussing on the creation of a so-called experience library in a complex spatial setting. The case was the joint public library of the municipalities of Hemiksem and Schelle near Antwerp, located in a former cistercienzer abbey with a subsequent use as a military depot until WWII and a present use as a public administrative center. The complexity of the spatial setting relates to (i) the vast surface, (ii) the subsequent spatial interventions in view of different historical destinations, (iii) the 'protected' heritage features of the building that may not be altered by the new design (i.e. juridical and spatial design constraints of the official heritage status).

\subsection{The features of the competence-based learning pocess}

During the three subsequent years, the teaching staff developed a set of various teaching activities that jointly gave rise to a competence-based learning process. The phases and various activities are:

- Phase 1 (September- October): a well-considered selection of interesting real-life cases. Therefore the selection is realized together with academic public library specialists and representatives of professional platforms (e.g. CULTUURCONNECT or the Flemish platform of Flemish Libraries and Local Culture Policy; VABB or the Association of Flemish Public Libraries and Archives);

- $\quad$ Phase 2 (November - December): an ex-ante prospection by the teaching staff in order to get a clear understanding of the societal challenges as well as the associated design challenges. As such, the real-life character of the assignment can be guaranteed;

- Phase 3 (first week of February): an intensive kick-off week in which the students are confronted with (i) lectures of national and international library experts (i.e. academics, architects, policy makers, ...), (ii) a set selected by the teaching staff of visual design references of national and international public libraries with similar societal challenges, (iii) a workshop in which the students themselves have to look for additional visual references in view of the particular assignment, (iv) various organized trips to 'inspiring' existing public libraries in Belgium and the Netherlands (e.g. Muntpunt in Brussels, the public library in Amsterdam, the chocolate factury library in Gouda, ...), (v) a visit to the actual sites of the cases involved and (vi) oral and written information given by several stakeholders involved (i.e. interviews, plans, photographs given by the library director, library staff members, the administrative coordinator of local culture policy, the alderman of culture policy, social workers, youth consultants, ...). This intensive kick-off week offers a broad 'bird'-perspective on the assignment (e.g. general library trends and hypes, contextual opportunities and constraints, existing designs or inspiration, conflicting demands of stakeholders). 
- $\quad$ Phase 4 (February-March): six weeks of in-depth research realized by student teams on a specific topic of each case (e.g. the location, the architectual plans and maps, the needs of the target groups involved, the historical background, the juridical opportunities and constraints). This teamwork is realized in groups of maximum eight students per topic. The results of the teamwork is compiled into a case-study documentation map given to all students involved. This in depth teamwork offers a more detailed perspective on the assignment and simulates in particular the intensive joint preparation that is needed in a future professional setting. This phase is coached by the teaching staff that gives an intermediate feedback at the end of every week. The feedback consists of content-wise comments related to the topic and of process-wise evaluations related to the organization and planning of the team;

- Phase 5 (April-June): eight weeks to elaborate an individual design that meets the particular requirements, setting and constraints of the case. Students are stimulated but not forced to initiate extra visits to the cases, have interviews with the stakeholders involved or consult additional documents. It is up to the students to organize entirely this part of the learning process. The end result should consist of four representation techniques frequently used in the academic and vocational world of interior architects, being (i) a plan or 2D representation, (ii) a maquette or 3D representation, (iii) several renderings or simulations of actual usage and appearance, and (iv) a study of used materials. Once again this phase is coached by the teaching staff who gives an intermediate feedback at the end of every week. The feedback consists of content-wise comments related to the design itself and of process-wise evaluations related to the organization and planning of each individual student;

- Phase 6 (First week of July): the evaluation of each elaborated design and its four representation techniques by a mixed jury. On the one hand the jury consists of the teaching staff and some additional designer-teachers of the Faculty, on the other hand it consists of several representatives of each case involved. Thus, students have also to convince potential clients who co-defined the assignment and quality of their elaborated design (i.e. public libraries). This phase simulates once again the future professional setting of interior designers. In particular this phase focusses on in-depth reflections made by all parties involved;

- Phase 7 (September and October): in the third year some additional activities were organized to enable some students - though on a voluntary basis - to continue the development of their social awareness competences. Thus, 7 students were given the opportunity to enter an organized contest by the Faculty for the 'best' design (including a voting round amongst present users of the library involved). And 17 students were asked to show and present their elaborated design to the general public of Hemiksem and Schelle (i.e. on the yearly Flemish Curltural Heritage Day). In this phase students were confronted with more general reflections made by a "non- 
designer' public and their perceptions of the societal role of a public library (e.g. what do I as a citizen of Hemiksem find important? What are my expectations towards our future public library?).

\section{Experiences of teachers and students: results of a qualitatieve data-analysis}

To check the realization of the initial ambitions, as well as to uncover interesting lessonslearned, qualitative data-gathering techniques were used throughout the entire project.

For the teaching staff intermediate, mainly informal focus group debates were organized to discuss the experiences of the feedback moments (e.g. what are the concerns and communicated challenges by the students themselves? what kind of design behavior of the students do we observe? In what way does the societal awareness changes throughout the learning process?) Additionally, the phase of the final jury also offers opportunities to reflect on the lessons learned, and this together with the representatives of the cases or the professional setting itself (e.g. what do they experience and observe in relation to the presence or development of the societal awareness throughout the learning process?).

The experiences of the students were not only registered during the intermediate feedback moments, but also after the finalization of the assignment (phase 6). In the second and third year an ad-random set of students were picked out for an in-depth half-structured interview of approximately 20 minutes. In the second year 18 students were interviewed or nearly $30 \%$ of 60 students, and in the third year 25 students or nearly $31 \%$ of 81 students. The inteviews were focussed on uncovering their own lessons learned in relation to (i) societal challenges of public libraries thoughout the entire assignment, and (ii) the relevance of this information for their own design and developed design competences (i.e. knowledge, skills and attitudes).

The results of the qualitative data-analysis of the experiences of the teaching staff, as well as the students can be summarized in the following four major lessons-learned:

- The ease and willingness with which young people in general (are supposed to) discover and understand evolutions in their broader habitat has clearly been overestimated. Thus, the societal awareness of the interior architect students was not easy to trigger, as several students also explicitly indicated during the in-depth interviews at the end. Of all the given information, documentation and confrontations, only a very limited amount was finally taken into explicit consideration. Many students only selected the information that was "directly" related to the interior discipline (e.g. "I'm an interior architect so I did not find the information given by library experts relevant. Too difficult to really understand"). In short, it seems to be 
rather difficult to remove the disciplinary filters and barriers of the students and to install a broader societal awareness that exceeds their own discipline;

- The ease and willingness to step out of a comfort-zone within their own discipline has also been overestimated. All staff members noticed for instance that the students always looked for the "shortest, safest and easiest way" to design, although they are taught otherwise. They mostly glimpse at the "safe" information given by the teaching staff and public libraries involved and rarely realize extra, self-planned observations or interviews. Additionally, the students reflect heavily on the technical and material interior requirements of the cases (e.g. length of bookshelves, available surface), and only to a limited extent on the perceptive and experience-related requirements (e.g. the evoked fascination). The latter is however crucial when using a societal awareness perspective on interior design;

- The way in which complex and difficult assignments trigger and motivate the students to actually leave their comfort-zone has clearly been underestimated. Mainly in the third year the assignment became rather complex, as also historical and juridical elements became part of the societal challenge of the case-study involved. At first the teaching staff and the students were afraid that this would jeopardize the willingness and capability to learn, but the opposite was true. Thus many interviewed students confirmed that the complexity and many constraints actually motivated them ".... to leave what I had learned partly behind and start to experiment. Otherwise the assignment was not feasible. And I admit, that was quite fascinating";

- The way in which the overall limited - absent - societal awareness within the interior discipline hinders the societal awareness building of students has also clearly been underestimated. Most arguments used by interior teachers and designers to explain and account for their own design is based on individual reflections, desires and fascinations, not on societal challenges that have to be solved. "How can we then expect students to behave otherwise and actually make an explicit societal or contextual link?" In short, and mainly according to the teaching staff it is clear that students are not only influenced by their curriculum or "what is taught", but also by what they actually observe themselves in the design behavior of teachers and famous and leading professionals in their discipline.

\section{Conclusion}

During three subsequent years, the faculty of Design Sciences of the University of Antwerp has developed a competence-based learning process focussed on the development of the societal awareness of their bachelor students in interior architecture. 
The essence of the learning process concerns a gradual evolvement of design-related activities focussed on five real-life case-studies of Flemish public libraries and their respective societal challenges. Throughout the three subsequent years approximately 220 students were involved, as well as a teaching staff of 4 to 6 colleagues. Although the development of the competence-based learning process is still proceeding, a first set of evaluative considerations has already been made on the basis of a qualitatieve-data analysis.

In this paper we have reported on the design of the competence-based learning pocess as well as on the intermediate considerations - experiences and reflections - of the teaching staff and students involved. In short, it concerns four lessons-learned relating to the overand underestimation of disciplinary filters, comfort-zones, (unexpected) motivating effects of complex assignments and copy-cat behavior.

In future and still to be written papers we will (i) elaborate the considerations more in depth, (ii) report on intermediate solutions with which the teaching staff tries to improve the learning process and remedy the uncovered over- and underestimations and (iii) elaborate a quantitative evaluation tool to measure and fine-tune the effects in a more rigorous way.

\section{References}

Aabo, S. (2005). The Role and Value of Public Libraries in the Age of Digital technologies. Journal of Librarianship and Information Science, 37(4), 205-211.

Attiwill, S. (2011). Urban and Interior: techniques for an urban interiorist, in: R. U. Hinkel (Ed.), Urban Interior. Informal explorations, interventions and occupations. Baunach (Germany): Spurbuchverlag, 11-24.

Burke, J. (1990) Competence based Education and Training. London: Falmer Press.

Caan, S. (2011). Rethinking Design and Interiors. Human Beings in the Built Environment. London: Laurence King Publishing.

Cunningham, E. (2014). Navigating the Past: What Does History Offer the Discipline of Interior Design?. Journal of Interior Design, 39(3), v-xi. doi: 10.1111/joid.12031.

Dahlkild, N. (2011). The Emergence and Challenge of the Modern Library Building: Ideal Types, Model Libraries, and Guidelines, from the Enlightenment to the Experience Economy. Library Trends, 60(1), 11-42.

Dunleavy, P., Magetts, H., Bastow, S. \& Tinker, J. (2006). New Public Management is Dead - Long Live Digital-Era Governance. Journal of Public Administration Research and Theory, 16, 467-494.

Giunta, E.E. (2009). Urban interiors. Artificial territories. Designing 'spatial script' for relational field. IDEA Journal(Interior Territories), 52-61.

Hoogveld A.W.M., Paas, F \& Jochems, W.M.G. (2005) Training higher education teachers for instructional design of competency-based education: Product-oriented versus process-oriented worked examples. Teaching and Teacher Education, 21(3), 287-297. 
Koliba, C., Meek, J.W. \& Zia, A. (2010). Governance Networks in Public Administration and Public Policy. New York: CRC Press, Taylor and Francis Group.

Vallet, N. (2015). The Odyssey of Flemish Public Libraries. Facing opportunities and threats when becoming strategic partners in urban development. Library Management, $36(8 / 9), 1-14$. 